\title{
An ectopic pheochromocytoma on cardiac metaiodobenzylguanidine scintigraphy in a patient with Takotsubo cardiomyopathy
}

\author{
Kenji Sadamatsu, Yuya Yoshidomi
}

\begin{abstract}
Introduction: Pheochromocytoma is one of the diseases that is known to cause Takotsubo cardiomyopathy, however, because of its rare occurrance a diagnosis of pheochromocytoma may be overlooked in patients with Takotsubo cardiomyopathy. Case Report: We report a case of a patient with Takotsubo cardiomyopathy which was discovered when the patient visited her doctor for consultation for a breast mass. During the visit she developed transient left ventricular dysfunction. Computed tomography scan detected a paraortic mass. After recovery, she underwent simultaneous operations for the breast cancer and the paraaortic mass and developed an acute hypertensive crisis. The paraaortic mass was diagnosed as ectopic pheochromocytoma. On retrospective examination, metaiodobenzyl- guanidine scintigraphy, which was undertaken previously to assess suspected Takotsubo cardiomyopathy, showed an abnormal uptake in the paraaortic mass which was suspicious for pheochromocytoma. Conclusion: Pheochromo-cytoma can be detected as an incidental finding on metaiodobenzylguanidine cardiac scintigraphy, which is used to evaluate patients with Takotsubo cardiomyopathy or heart failure.
\end{abstract}

Kenji Sadamatsu ${ }^{1}$, Yuya Yoshidomi ${ }^{2}$

Affiliations: ${ }^{1}$ Director of the Department of Cardiology, Saga Prefectural Hospital Koseikan, Saga, Japan; ${ }^{2}$ Resident Physician, Department of Cardiology, Saga Prefectural Hospital Koseikan, Saga, Japan

Corresponding Author: Kenji Sadamatsu, Department of Cardiology, Saga Prefectural Hospital Koseikan, 1-12-9 Mizugae, Saga, Japan. 840-8571; Ph: 81-952-24-2171; Fax: 81-952-29-9390; Email: k-sadamatsu@umin.ac.jp

Received: 08 June 2012

Accepted: 24 July 2012

Published: 01 March 2013
Keywords: Radioisotope, Catecholamine, Computed tomography, Paraganglioma, Metaiodobenzylguanidine

$$
* * * * * * * * *
$$

Sadamatsu K, Yoshidomi Y. An ectopic pheochromocytoma on cardiac metaiodobenzylguanidine scintigraphy in a patient with Takotsubo cardiomyopathy. International Journal of Case Reports and Images 2013;4(3):180-183.

$$
* * * * * * * *
$$

doi:10.5348/ijcri-2013-03-289-CR-10

\section{INTRODUCTION}

Takotsubo cardiomyopathy has been widely recognized as a differential diagnosis for patients with chest pain. Several mechanisms, including microvascular dysfunction, have been proposed as a possible cause of this disorder. The abnormal uptake on Iodine-123 labelled metaiodobenzylguanidine cardiac scintigraphy suggests that an excessive release of catecholamines has an important role in the pathophysiology of the disease $\left[\begin{array}{ll}1, & 2\end{array}\right]$. Pheochromocytoma is one of the diseases that is known to cause reversible left ventricular dysfunction, however, because of it rare occurrance its diagnosis may be missed in patients with Takotsubo cardiomyopathy.

\section{CASE REPORT}

A 61-year-old female who was visiting a doctor for consultation for the presence of a breast mass, suddenly developed headache and chest pain and therefore was transferred to a hospital. Although her electrocardiogram revealed no significant ST-T change, the troponin I level was $3.57 \mathrm{ng} / \mathrm{mL}$. Coronary angiography was normal and left ventriculography demonstrated anterior hypokinesis 
at the mid-ventricular level (Figure 1A-B). Transient inversions of $\mathrm{T}$ waves in the anterolateral leads and normalization of the abnormal wall motion in the following days led to a diagnosis of Takotsubo cardiomyopathy. Iodine-123 labelled metaiodobenzylguanidine cardiac scintigraphy demonstrated anterolateral defects in the delayed phase and the heart to mediastinum ratio increased to 2.5.

Computed tomography (CT) scan demonstrated a paraaortic mass in her left abdomen (Figure 1C). She underwent simultaneous operations for the breast cancer and the paraaortic mass. When a surgeon manipulated the mass during the operation. Her blood pressure rapidly increased to over $200 \mathrm{mmHg}$, with ventricular tachycardia. Diagnostic studies performed after stopping the operation showed pulmonary congestion and anterior hypokinesis with $\mathrm{T}$ wave inversions in the leads I, II, III, aVL, aVF and V2-6. The retrospective findings of metaiodobenzylguanidine scintigraphy showed an abnormal uptake in the paraaortic mass (Figure 1D). Further examinations of the mass resulted in a diagnosis of ectopic pheochromocytoma, also known as a paraganglioma, which was successfully resected. The histological findings of the mass demostrated that almost all the tumor cells were round with an eosinophilic, granular cytoplasm and that they were arranged in compact cell nests called Zellballen. Immunohistochemical staining showed positive results for chromogranin A and negative results for calretinin and Ki-67. Genetic testing was not performed because of patient's negative falimily history. She was discharged without any perioperative complications and was administered

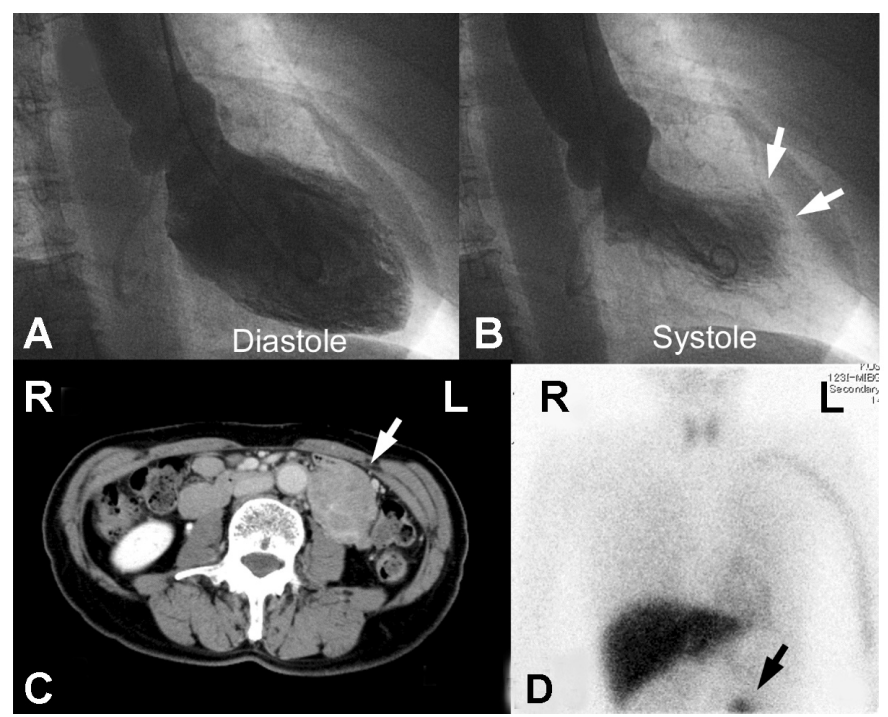

Figure 1: Left ventriculography at the first admission at (A) end-systole and (B) end-diastole showed anterior hypokinesis (arrows) at the mid-ventricular level, (C) Abdominal computed tomography scan showed a $4.2 \times 4.0 \times 7.7 \mathrm{~cm}$ heterogeneously enhanced mass (arrow) in the left abdomen, (D) Iodine-123 metaiodobenzylguanidine planar imaging demonstrated an abnormal uptake in the left abdomen (arrow), which was accordant to the site of the paraaortic mass. postoperative chemotherapy for breast cancer. One year after the operation, CT scan did not demonstrate any evidance of recurrence of the pheochromocytoma or the breast cancer.

\section{DISCUSSION}

Cardiac scintigraphy with Iodine-123 labelled metaiodobenzylguanidine, a radiopharmaceutical agent that is taken up by adrenergic nerve endings, has been reported to be useful in patients with heart failure or left ventricular dysfunction. A reduced uptake ratio of the heart to the mediastinum on the planar image has an independent prognostic value in patients with symptomatic heart failure [3]. In patients with Takotsubo cardiomyopathy, myocardial metaiodobenzylguanidine scintigraphy can reveal transient defects and a high washout ratio $[1,4]$, which suggests that there is an impaired activity of the sympathetic nervous system in such patients. On the other hand, metaiodobenzylguanidine scintigraphy has also been used for detecting pheochromocytoma inspite of the difference of labelling with Iodine-123 or iodine131 [5], and has a high sensitivity of $77-100 \%$ and a specificity of $95-100 \%$ [6]. Diagnostic imaging is useful for both the diseases and the incidental finding of pheochromocytoma by metaiodobenzylguanidine cardiac scintigraphy is possible. However, the diagnosis of pheochromocytoma might be difficult without a suspicion [7], because the pheochromocytoma is considered a rare disease, and thus the entire findings of Iodine-123 labelled metaiodobenzylguanidine cardiac scintigraphy must be carefully reviewed in patients with heart failure and/or Takotsubo cardiomyopathy. In addition, the pheochromocytoma can be an etiology of heart failure and/or Takotsubo cardiomyopathy [8]. Metaiodobenzylguanidine scintigraphy might also serve as a single step assessment to predict the prognosis and to rule out the etiology for patients with heart failure and/or Takotsubo cardiomyopathy.

The recurrence of pheochromocytoma and Takotsubo cardiomyopathy is not rare and the surgical removal of a pheochromocytoma does not necessarily lead to a longterm cure of pheochromocytoma or hypertension, even in the case of a benign tumor. The recurrence rate of pheochromocytoma is reported to be $16 \%$, and recurrence is more likely in patients with familial pheochromocytoma or familial paraganglioma, right adrenal tumors and extra-adrenal tumors [9]. The recurrence rate of Takotsubo cardiomyopathy has been reported to be $1.6-11.4 \%$ [10], and this type of cardiac dysfunction sometimes results in hemodynamic collapse, although the transient left ventricular dysfunction in our case was dependent on the attacks of the pheochromocytoma. Therefore, long-term monitoring is indicated in such patient for the recurrence of pheochromocytoma with Takotsubo cardiomyopathy. 


\section{CONCLUSION}

Pheochromocytoma can be detected as an incidental finding on metaiodobenzylguanidine cardiac scintigraphy done for evaluating patients with Takotsubo cardiomyopathy or heart failure.

\section{$* * * * * * * * *$}

\section{Acknowledgements}

The authors wish to thank Dr. Daisuke Mori for his evaluation of the pheochromocytoma specimen.

\section{Author Contributions}

Kenji Sadamatsu - Conception and design, Acquisition of data, Analysis and interpretation of data, Drafting the article, Critical revision of the article, Final approval of the version to be published

Yuya Yoshidomi - Acquisition of data, Analysis and interpretation of data, Drafting the article, Final approval of the version to be published

\section{Guarantor}

The corresponding author is the guarantor of submission.

\section{Conflict of Interest}

Authors declare no conflict of interest.

\section{Copyright}

(C) Kenji Sadamatsu et al. 2013; This article is distributed under the terms of Creative Commons Attribution 3.0 License which permits unrestricted use, distribution and reproduction in any means provided the original authors and original publisher are properly credited. (Please see www.ijcasereportsandimages.com /copyright-policy.php for more information.)

\section{REFERENCES}

1. Sadamatsu K, Tashiro H, Maehira N, Yamamoto K. Coronary microvascular abnormality in the reversible systolic dysfunction observed after noncardiac disease. Jpn Circ J 2000;64(10):789-2.

2. Lyon AR, Rees PS, Prasad S, Poole-Wilson PA, Harding SE. Stress (Takotsubo) cardiomyopathy--a novel pathophysiological hypothesis to explain catecholamine-induced acute myocardial stunning. Nat Clin Pract Cardiovasc Med 2008;5(1):22-9.

3. Jacobson AF, Senior R, Cerqueira MD, et al. Myocardial iodine-123 meta-iodobenzylguanidine imaging and cardiac events in heart failure. Results of the prospective ADMIRE-HF (AdreView Myocardial Imaging for Risk Evaluation in Heart Failure) study. J Am Coll Cardiol 2010;55(20):2212-21.

4. Tsuchihashi $\mathrm{K}$, Ueshima $\mathrm{K}$, Uchida $\mathrm{T}$, et al. Transient left ventricular apical ballooning without coronary artery stenosis: a novel heart syndrome mimicking acute myocardial infarction. Angina Pectoris-Myocardial Infarction Investigations in Japan. J Am Coll Cardiol 2001;38(1):11-8.
5. Fukuoka M, Taki J, Mochizuki T, Kinuya S. Comparison of diagnostic value of I-123 MIBG and high-dose I-131 MIBG scintigraphy including incremental value of SPECT/CT over planar image in patients with malignant pheochromocytoma/paraganglioma and neuroblastoma. Clin Nucl Med 2011;36(1):1-7.

6. Ilias I, Pacak K. Current approaches and recommended algorithm for the diagnostic localization of pheochromocytoma. J Clin Endocrinol Metab 2004;89(2):479-91.

7. Hwang BH, Kim HY, Jung SE, Park KW. Extraadrenal pheochromocytoma after operation of congenital heart disease: a case report of 18-year-old boy. J Korean Surg Soc 2012;83(1):65-8.

8. Prejbisz A, Lenders JWM, Eisenhofer G, Januszewicz A. Cardiovascular manifestations of pheochromocytoma. H Hypertens 2011;29(11):2049-60.

9. Amar L, Servais A, Gimenez-Roqueplo AP, Zinzindohoue F, Chatellier G, Plouin PF. Year of diagnosis, features at presentation, and risk of recurrence in patients with pheochromocytoma or secreting paraganglioma. J Clin Endocrinol Metab 2005;90(4):2110-16.

10. Tokunou T, Sadamatsu K. Recurrence of Takotsubo cardiomyopathy with coronary slow flow phenomenon. J Cardiol Case 2012;5(2):e100-6. 
Access full text article on other devices

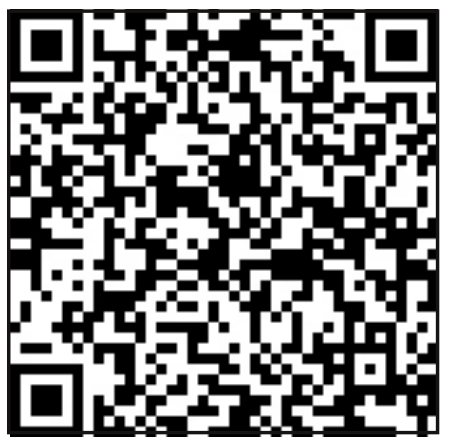

Access PDF of article on other devices

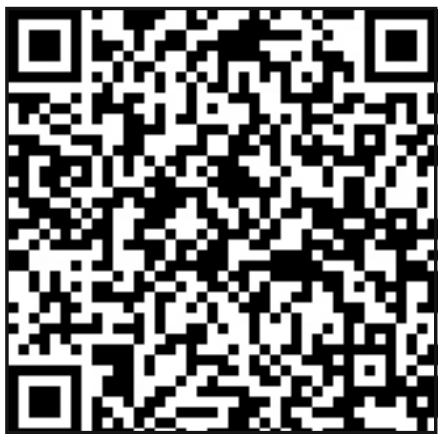

